\title{
A Word of Caution regarding Risk Factors for Malignant Transformation of Choroidal Nevi
}

\author{
Gustav Stålhammar ${ }^{a, b}$

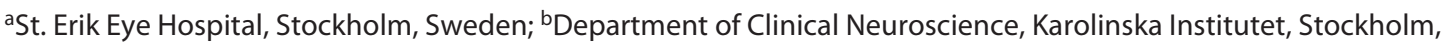 \\ Sweden
}

\section{Dear Editor,}

It is with great interest I read the recently published editorial by Singh and Grossniklaus [1] and the research study by Raval et al. [2] regarding the distinction between choroidal nevi and small choroidal melanomas. The authors should be commended for highlighting a central yet often overlooked issue and for investigating the correlation of growth with histopathological findings. The latter is a much-needed effort in a field where patients rarely undergo diagnostic biopsy prior to treatment.

Following pioneering work by Dr. Gass some 50 years ago, as well as later additions by others, Dr. Shields and colleagues coined a widely recognized mnemonic to help us remember risk factors for growth of choroidal nevi into melanoma: "To find small ocular melanoma using helpful hints daily," (TFSOMUHHD) [3-8]. In 2019, an updated version of the mnemonic was offered: "To find small ocular melanoma doing imaging” (TFSOMDI), representing thickness $>2 \mathrm{~mm}$ (by ultrasound), subretinal fluid (by OCT), symptoms of vision loss, orange pigment (by autofluorescence), melanoma hollow (by ultrasound), and diameter $>5 \mathrm{~mm}$ (by photography) [9].

Mnemonics are useful tools for remembering risk factors. By reminding us to evaluate each parameter, they may increase diagnostic accuracy and reproducibility and help us avoid delays in the treatment of choroidal melanomas. My respected colleagues should be praised for these contributions. Nevertheless, caution is warranted. In addition to what is highlighted by Singh and Grossniklaus [1], 3 more issues may be mentioned.

The first problem is one of the criteria for classification: if risk factors for malignant transformation are similar or identical to the parameters used for diagnosing choroidal melanoma, the two will correlate regardless of the true biology of the lesion. In the 2009 and 2019 publications by Shields et al. [8, 9], malignant transformation was defined as "enlargement in the basal dimension or thickness of at least $0.5 \mathrm{~mm}$ " and "enlargement in basal dimension or thickness by at least $0.5 \mathrm{~mm}$ (arbitrary) over a short time period," respectively. In other words, TFSOMUHHD and TFSOMDI have not actually been shown to identify malignancy, but growth by $0.5 \mathrm{~mm}$. Growth is not the only hallmark of cancer, and very small tumors can harbor BAP1 mutations and seed metastases [10-13]. Further, in a 2019 publication, Dr. Harbour and colleagues [14] found that documented growth of choroidal nevi was not associated with malignant transformation. The latter was defined as having the highly metastatic
C 2021 The Author(s).

Published by S. Karger AG, Basel

This is an Open Access article licensed under the Creative Commons Attribution-NonCommercial-4.0 International License (CC BY-NC) (http://www.karger.com/Services/OpenAccessLicense), applicable to the online version of the article only. Usage and distribution for commercial purposes requires written permission.
Correspondence to:

Gustav Stålhammar, gustav.stalhammar@ki.se 


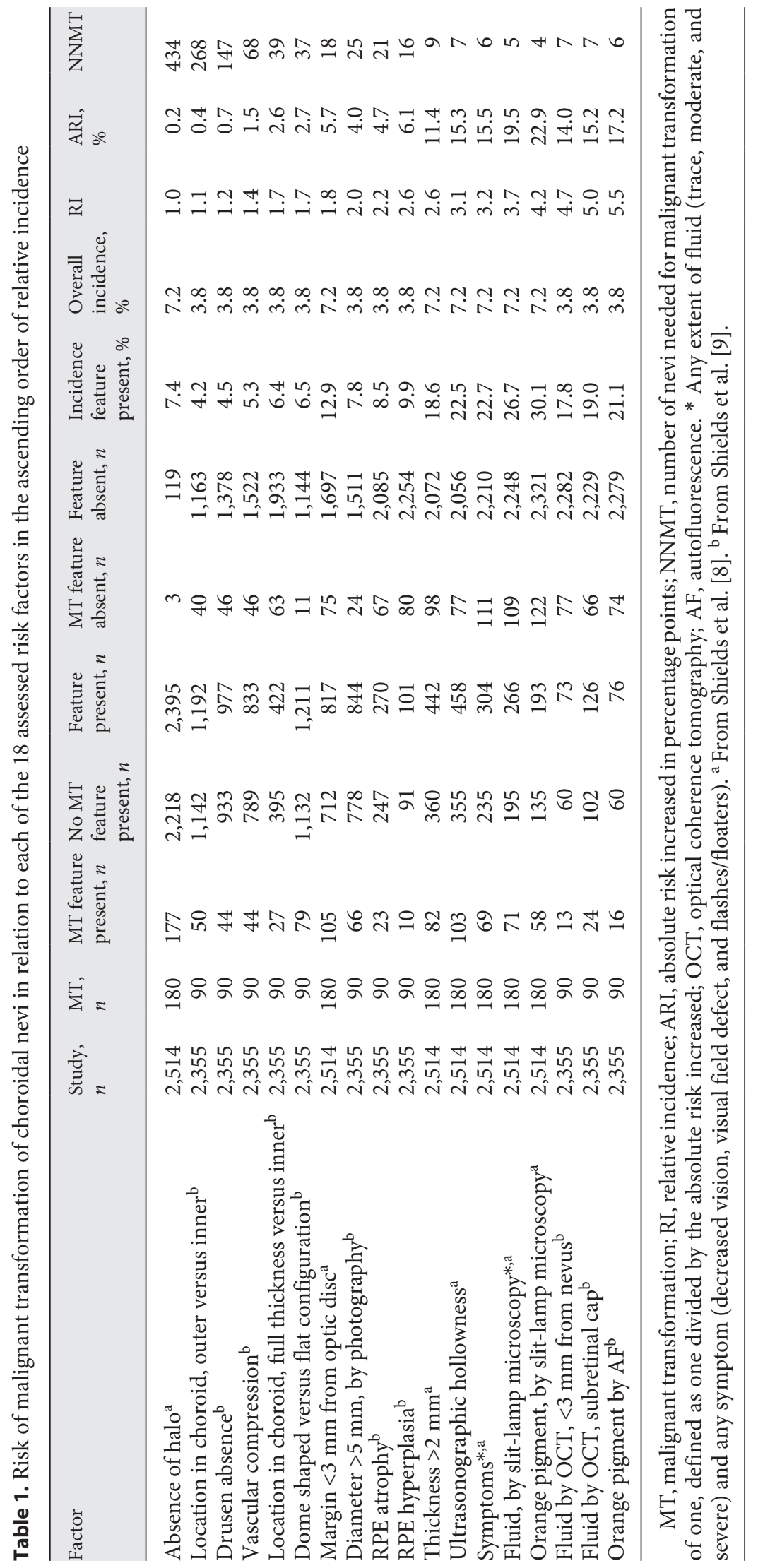




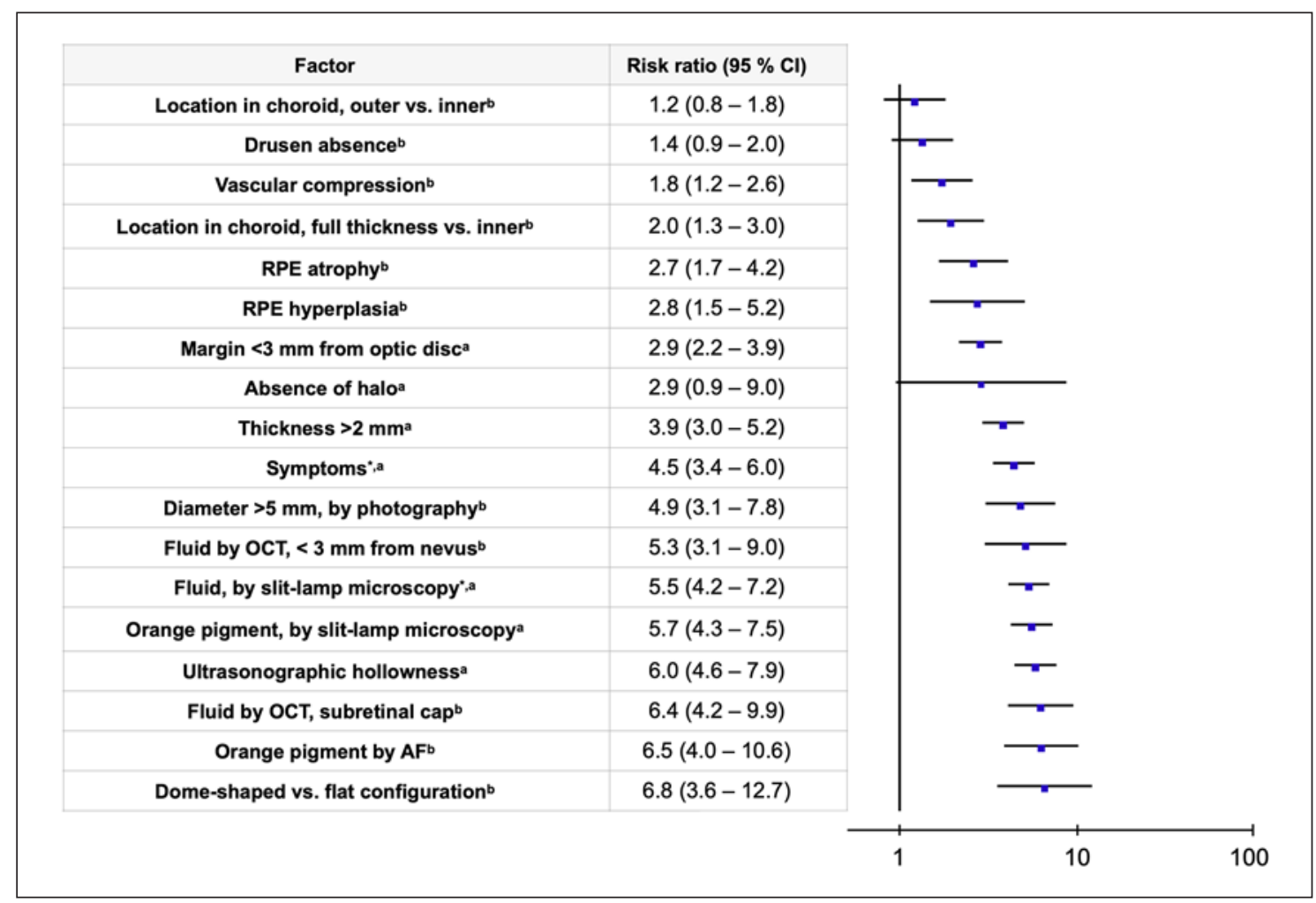

Fig. 1. Risk ratios for malignant transformation in presence versus absence of 18 risk factors in the ascending order. Random effects Mantel-Haenszel model. CI, confidence interval. a From Shields et al. [8]. ${ }^{\text {b}}$ From Shields et al. [9].

gene expression class 2. But, far from all choroidal melanomas have gene expression class 2 and metastases do occur from class $1 \mathrm{~A}$ and $1 \mathrm{~B}$ tumors [15]. Both the concept of using gene expression class 2 and $0.5 \mathrm{~mm}$ growth as definitions of malignant transformation of nevi must therefore be questioned.

The second problem is one of representativity: the risk factors were identified in cohorts with incidences of malignant transformation (or more precisely: $0.5 \mathrm{~mm}$ growth) of 7.2 and $2.4 \%$, respectively $[8,9]$. This is $12-36$ times higher than the calculated $0.2 \%$ risk of malignant transformation of choroidal nevi in the general population [16]. Consequently, the included risk factors may not be representative of all nevi.

The third and the last problem is one of the statistical methods. In the 2009 and 2019 publications by Shields et al. $[8,9]$, the number of nevi with specific risk factors was reported in "growth into melanoma" and "no growth into melanoma" groups. The opposite may however be more relevant to the clinical setting: to report the risk of malignant transformation in the presence of a specific risk factor.
I have therefore proceeded with calculations of the relative incidence, absolute risk increased, and number needed for malignant transformation (NNMT) based on the original data from the two articles $[8,9]$. Further, the risk ratio and $95 \%$ confidence interval were calculated for each risk factor. Risk ratios were calculated using a random effects Mantel-Haenszel model with the Review Manager by the Cochrane Collaboration (RevMan Version 5.4; The Cochrane Collaboration, Copenhagen, Denmark, 2014). Positive and negative predictive values were not calculated, as it would give a misleading picture. For example, the positive predictive value of absence of halo was $7.4 \%$ in one of the cohorts. This may seem to indicate a valid prognostic test until we realize that the overall incidence of malignant transformation in the cohort regardless of risk factors was 7.2\% [8]. Other potential risk factors, such as the ones included in the recently proposed MOLES mnemonic, are not included [17]. Not least since the latter is not intended to identify lesions that will undergo malignant transformation or grow in the future. 
A total of 18 risk factors were evaluated. Of these, $8 \mathrm{had}$ statistically weak importance for malignant transformation with relative incidences $\leq 2$ and absolute risk increased $\leq 10 \%$ (Table 1). These 8 risk factors included absence of halo, absence of drusen, and margin $<3 \mathrm{~mm}$ from the optic disc, which were included in the older mnemonic, and diameter $>5 \mathrm{~mm}$ by photography, which was included in the newer mnemonic. In analysis of relative risk, absence of halo, absence of drusen, and location in the choroid outer versus inner were not statistically significant. Further, the very strongest risk factor was not included in any of the mnemonics: dome shaped versus flat configuration, with a risk ratio of 6.8 (95\% CI: 3.6-12.7, Fig. 1).

These findings have several limitations. Foremost, they are based on previously published group level and not individual raw data, preventing multivariate regression analysis. Several factors are likely correlated, including dome shape and thickness. In line with previous publications, the risk factors are presented as dichotomized options, for example, orange pigment or dome shape "yes" or "no," whereas such distinctions can be less than obvious in clinical reality.

Nevertheless, one can conclude that in addition to the background problems of classifications and representativity that warrant caution when using all the currently available risk factors for malignant transformation of choroidal nevi, some of them have statistically weak importance even within their own original data and logical framework. Increased awareness of these issues and examinations of the true biology of small choroidal melanocytic lesions are key to resolving this matter. The publications by Singh and Grossniklaus [1] and Raval et al. [2] are a good start.

\section{Statement of Ethics}

The research was conducted in accordance with the Declaration of Helsinki. According to the Swedish Ethical Review Act (law section 2003:460), ethical approval and consent to participate was not required as all work presented herein was based on publicly available anonymized group level data that cannot be used to identify any individuals. No personal, sensitive, or pseudonymized information was accessed. No interventions, treatments, meetings, or other contacts with patients or relatives were carried out, and no tissues or other biological samples were used.

\section{Conflict of Interest Statement}

The author has no conflicts of interest to declare.

\section{Funding Sources}

Support for this study was provided to Gustav Stålhammar from The Royal Swedish Academy of Sciences (reference ME20190036); The Swedish Cancer Society (20 0798 Fk); The Swedish Society of Medicine (Cronqvists stiftelse, reference SLS 934014); The Swedish Eye Foundation (reference 2021-04-28); Karolinska Institutet (reference 2019-01900, 2020-013333, and 2020-02517); Region Stockholm (reference 20200356); The Crown Princess Margareta Foundation for the Visually Impaired (reference 157); and Carmen and Bertil Regnér Foundation (reference 2020-00062). The funding organizations had no role in the design or conduct of this research.

\section{Data Availability Statement}

The data used for this work are publicly available in the articles by Shields et al. [8] (Table 3) and Shields et al. [9] (Table 6).

\section{References}

1 Singh AD, Grossniklaus HE. What's in a name? Large choroidal nevus, small choroidal melanoma, or indeterminate melanocytic tumor. Ocul Oncol Pathol. 2021.

2 Raval V, Luo S, Zabor EC, Singh AD. Small choroidal melanoma: correlation of growth rate with pathology. Ocul Oncol Pathol. 2021: 1.

3 Gass JD. Fluorescein angiography. An aid in the differential diagnosis of intraocular tumors. Int Ophthalmol Clin. 1972;12(1):85120.

4 Gass JD. Problems in the differential diagnosis of choroidal nevi and malignant melanoma. XXXIII Edward Jackson memorial lecture. Trans Sect Ophthalmol Am Acad Ophthalmol Otolaryngol. 1977 Jan-Feb;83(1): 19-48.
5 Butler P, Char DH, Zarbin M, Kroll S. Natural history of indeterminate pigmented choroidal tumors. Ophthalmology. 1994 Apr;101(4): 710-7; discussion 17

6 Shields CL, Shields JA, Kiratli H, De Potter P, Cater JR. Risk factors for growth and metastasis of small choroidal melanocytic lesions. Ophthalmology. 1995;102:1351-61; discussion 75-9.

7 Melia BM, Diener-West M, Bennett SR, Folk JC, Montague PR, Weingeist TA, et al. Factors predictive of growth and treatment of small choroidal melanoma: COMS report no. 5. Arch Ophthalmol. 1997;115(12):1537-44.
8 Shields CL, Furuta M, Berman EL, Zahler JD, Hoberman DM, Dinh DH, et al. Choroidal nevus transformation into melanoma: analysis of 2,514 consecutive cases. Arch Ophthalmol. 2009 Aug;127(8):981-7.

9 Shields CL, Dalvin LA, Ancona-Lezama D, Yu MD, Di Nicola M, Williams BK Jr, et al. Choroidal nevus imaging features in 3,806 cases and risk factors for transformation into melanoma in 2,355 cases: the 2020 Taylor R. Smith and Victor T. Curtin lecture. Retina. 2019 Oct;39(10):1840-51.

10 Hanahan D, Weinberg RA. Hallmarks of cancer: the next generation. Cell. 2011;144(5): 646-74.
Regarding Risk Factors for Malignant Transformation of Choroidal Nevi
Ocul Oncol Pathol 2021;7:376-380 DOI: $10.1159 / 000518868$ 
11 Jouhi S, Jager MJ, de Geus SJR, Desjardins L, Eide NA, Grange JD, et al. The Small Fatal Choroidal Melanoma Study. A survey by the European Ophthalmic Oncology Group. Am J Ophthalmol. 2019 Jun;202:100-8.

12 Herrspiegel C, Kvanta A, Lardner E, Ramsköld Cabaca L, Wells J, Bartuma K, et al. Nuclear expression of BAP-1 in transvitreal incisional biopsies and subsequent enucleation of eyes with posterior choroidal melanoma. $\mathrm{Br}$ Ophthalmol. 2021 Apr;105(4):582-6.
13 Uner OE, See TRO, Szalai E, Grossniklaus HE, Stålhammar G. Estimation of the timing of BAP1 mutation in uveal melanoma progression. Sci Rep. 2021 Apr 26;11(1):8923.

14 Harbour JW, Paez-Escamilla M, Cai L, Walter SD, Augsburger JJ, Correa ZM. Are risk factors for growth of choroidal nevi associated with malignant transformation? Assessment with a validated genomic biomarker. Am J Ophthalmol. 2019 Jan;197:168-79.
15 Aaberg TM, Covington KR, Tsai T, Shildkrot Y, Plasseraud KM, Alsina KM, et al. Gene expression profiling in uveal melanoma: fiveyear prospective outcomes and meta-analysis. Ocul Oncol Pathol. 2020 Oct;6(5):360-7.

16 Kivela T, Eskelin S. Transformation of nevus to melanoma. Ophthalmology. 2006 May; 113(5):887-8.e1.

17 Al Harby L, Sagoo MS, O’Day R, Hay G, Arora AK, Keane PA, et al. Distinguishing choroidal nevi from melanomas using the MOLES algorithm: evaluation in an ocular nevus clinic. Ocul Oncol Pathol. 2021:1. 